\title{
Changing paradigms in the management of diabetic retinopathy
}

Abbreviations: DME, diabetic macular edema; DR, diabetic retinopathy; VEGF, vascular endothelial growth factor; OCT, optical coherence tomography

\section{Editorial}

Estimates suggest that the number of patients suffering from diabetes and its complications is growing exponentially. In the next few decades, statistics show that with the number of individuals diagnosed with diabetes may cross 400 million world-over by $2030 .{ }^{1}$ In the face of this challenge, it is imperative for ophthalmologists to devise strategies in order to tackle the high numbers of patients with diabetes-related blinding conditions. With a more severe disease, the likelihood of higher grades of retinopathy and nephropathy increase. Presently, one in 25 individuals above 40 years of age suffers from moderate visual loss due to diabetic macular edema (DME) leading to high visual morbidity. ${ }^{2}$ Therefore, it is necessary that newer paradigms in the management of diabetic retinopathy (DR) and DME are applied to overcome this great unmet need. ${ }^{3,4}$ In the past two decades, there has been a major shift in the treatment strategy for DME and DR. With the increasing recognition of the critical role of vascular endothelial growth factor (VEGF) in the pathogenesis of DR and DME, ${ }^{5}$ management of this condition is now focused on antagonizing this biochemical pathway. Large multicenter clinical trials have provided evidence of the high efficacy of anti-VEGF agents as well as steroids in the management of DR and DME.,

\section{Anti-VEGF therapy: newer advances}

Currently, intravitreal anti-VEGF therapy has become the mainstay of the management of DME and DR associated with DME. Ever since ranibizumab (Lucentis ${ }^{\circledR}$ ) was approved for the treatment of DME (August 2012), followed by Aflibercept (Eylea $\left.{ }^{\circledR}\right)$, (approved in July 2014), optical coherence tomography (OCT)-based monthly/frequent injection of these agents has become the standard of care. ${ }^{3}$ In addition to ranibizumab and aflibercept, bevacizumab is another efficacious agent in the management of DME. ${ }^{8}$ Therefore, these three anti-VEGF agents provide the most favorable visual outcomes compared to any other agent that have been used in the treatment of DME. The Diabetic Retinopathy Clinical Research network (DRCR.net) Protocol T study provided a direct head-to-head comparison of the efficacy of these three agents for the management of DME. ${ }^{9}$

The results of this study showed that all three agents provide similar improvement in visual and anatomical outcome (macular thickness) at the end of two years, though aflibercept may perform better in the first year of treatment in those who have visual acuity less than 20/50 at presentation. Given the high efficacy of anti-VEGF agents in the management of DME, the use of ranibizumab has been recently approved for the treatment of background DR in the presence of DME. ${ }^{7}$ Other indications of anti-VEGF include pre-surgical use for patients with large neovascular fronds planned for vitrectomy.

\section{Corticosteroids: current role}

Corticosteroids also have a major role in the management of DME and DR. Dexamethasone implant (Ozurdex$\left.{ }^{\circledR}\right) .{ }^{10}$ and fluocinolone

\author{
Volume 6 Issue 2 - 2017
}

\author{
Aniruddha Agarwal, Jagat Ram \\ Advanced Eye Center, Post Graduate Institute of Medical \\ Education and Research PGIMER, India
}

Correspondence: Jagat Ram, Professor Advanced Eye Centre, Department of Ophthalmology, Post Graduate Institute of Medical Education and Research Chandigarh 1600 I2, India, Tel 91-172-2747837, Email drjagatram@gmail.com

Received: January 29, 2017 | Published: January 31, 2017

acetonide insert (Iluvien $\left.{ }^{\circledR}\right){ }^{11}$ are two depot corticosteroid agents that have been approved in September 2014 for the treatment of DME. Iluvien ${ }^{\circledR}$ has been approved for use in patients who have been previously treated with corticosteroids and did not have a significant rise of intraocular pressure.

\section{Future therapies}

In addition to anti-VEGF agents and corticosteroids, newer agents have been introduced for the management of DME. These include antagonists of insulin-like growth factor (IGF-1), inhibitor of vascular endothelial-protein tyrosine phosphatase (VE-PTP) that activates TIE-2 (angiopoietin) receptor, and designated ankyrin repeat proteins (DARPin) that bind to VEGF and have a longer duration of action. Scientific breakthroughs have also led to the use of personalized medicine in the management of DME by identifying genotypes responsible for abnormal biochemical activation. ${ }^{12,13}$ As advances continue in the field of medicine, it is expected that the outcomes of patients with DR and DME will continue to improve. In the next few decades, it is likely that a new era in the management of patients with diabetes may set in.

\section{Acknowledgments}

None.

\section{Conflicts of interest}

The authors declare that there is no conflict of interest.

\section{Funding}

None.

\section{References}

1. Antonetti DA, Klein R, Gardner TW. Diabetic retinopathy. N Engl J Med. 2012;366(13):1227-1239.

2. Varma R, Bressler NM, Doan QV, et al. Prevalence of and risk factors for diabetic macular edema in the United States. JAMA ophthalmology. 2014;132(11):1334-1340.

3. Agarwal A, Sarwar S, Sepah YJ, et al. What have we learnt about the management of diabetic macular edema in the antivascular endothelial growth factor and corticosteroid era? Curr Opin Ophthalmol. 2015;26(3):177-183. 
4. Moss SE, Klein R, Klein BE. The 14-year incidence of visual loss in a diabetic population. Ophthalmology. 1998;105(6):998-1003.

5. Nguyen QD, Tatlipinar S, Shah SM, et al. Vascular endothelial growth factor is a critical stimulus for diabetic macular edema. Am J Ophthalmol. 2006;142(6):961-969.

6. Demirel S, Argo C, Agarwal A, et al. Updates on the Clinical Trials in Diabetic Macular Edema. Middle East Afr J Ophthalmol. 2016;23(1):3-12.

7. Agarwal A, Afridi R, Hassan M, et al. Novel Therapies in Development for Diabetic Macular Edema. Curr Diab Rep. 2015;15(10):75.

8. Rajendram R, Fraser-Bell S, Kaines A, et al. A 2-year prospective randomized controlled trial of intravitreal bevacizumab or laser therapy (BOLT) in the management of diabetic macular edema: 24-month data: report 3. Arch Ophthalmol. 2012;130(8):972-979.

9. Heier JS, Bressler NM, Avery RL, et al. Comparison of Aflibercept, Bevacizumab, and Ranibizumab for Treatment of Diabetic Macular Edema: Extrapolation of Data to Clinical Practice. JAMA ophthalmology. 2016;134(1):95-99.
10. Boyer DS, Yoon YH, Belfort R, et al. Three-year, randomized, shamcontrolled trial of dexamethasone intravitreal implant in patients with diabetic macular edema. Ophthalmology. 2014;121(10):1904-1914.

11. Cunha-Vaz J, Ashton P, Iezzi R, et al. Sustained delivery fluocinolone acetonide vitreous implants: long-term benefit in patients with chronic diabetic macular edema. Ophthalmology. 2014;121(10):1892-1903.

12. Agarwal A, Soliman MK, Sepah YJ, et al. Diabetic retinopathy: variations in patient therapeutic outcomes and pharmacogenomics. Pharmgenomics Pers Med. 2014;7:399-409.

13. Agarwal A, Ingham SA, Harkins KA, et al. The role of pharmacogenetics and advances in gene therapy in the treatment of diabetic retinopathy. Pharmacogenomics. 2016;17(3):309-320. 